\title{
RAZGLEDI
}

\section{PRISPEVEK K SLOVENSKI TERMINOLOGIJI KRASA IN KRAŠKIH OBLIK NA EOGENETSKIH KVARTARNIH KALKARENITIH}

\author{
AVTOR \\ dr. Matej Lipar \\ 10/224 West Coast Highway, Scarborough 6019, Western Australia, Avstralija \\ matej.lipar@gmail.com
}

DOI: $10.3986 / G V 88105$

UDK: 551.44:001.4

COBISS: 1.02

\section{IZVLEČEK}

Prispevek slovenski terminologiji krasa in kraških oblik na eogenetskih kvartarnih kalkarenitih $V$ slovenskih znanstvenih revijah se $v$ vse večji meri objavljajo opisi različnih tipov krasa po svetu in na njih vezanih reliefnih oblik. Za določene oblike, ki se v Sloveniji ne pojavljajo, ni obstoječih slovenskih izrazov, zato lahko ob različnih prevodih pride do zmede. V pričujočem članku so na primerih predlaganih novih slovenskih terminov opisani glavni tipi krasa in kraških oblik na kvartarnih eogenetskih kalkarenitih. Besedilo naj služi kot terminološko vodilo nadaljnjim poimenovanjem predstavljenih kraških pojavov in oblik.

KLJUČNE BESEDE

kraška terminologija, speleogeneza, singenetski kras, eogenetski kras, korozijske cevi, stolpiči, jame

\begin{abstract}
A contribution to Slovenian terminology of karst and its features developed in eogenetic Quaternary calcarenites

Different types of karst and its features are being continuously published in Slovenian scientific literature. However, for certain features there are no formal Slovenian terms which might lead to confusion. In this paper, terms in Slovene and general descriptions of different types of karst and its features of Quaternary eogenetic calcarenites are presented. The paper may serve as a reference to additional up-coming Slovenian literature about this kind of karst and its features.
\end{abstract}

KEY WORDS

karst terminology, speleogenesis, syngenetic karst, eogenetic karst, solution pipes, pinnacles, caves

Uredništvo je prispevek prejelo 3. julija 2016. 


\section{Uvod}

Kraška terminologija se zaradi novih spoznanj in idej nenehno dopolnjuje, poenostavlja ali zapleta. Iz slovenske terminologije so se v mednarodne izraze za kraške pojave razvili izrazi kot so doline (slovensko vrtača), polje (slovensko kraško polje) in ponor (slovensko ponor). Prav tako so v mednarodno veljavo stopili izrazi iz drugih jezikov, navadno tistih, v katerih so bili določeni kraški pojavi prvič ali pogosteje opisani ali pa so ti pojavi značilni del pokrajine določenih držav. Tako so na primer iz kitajske krasoslovne terminologije $\mathrm{v}$ mednarodno rabo prešli izrazi kot so fengcong, fenglin in shilin, iz madagaskarske tsingy ter iz jamajške cockpit.

Kljub mednarodni strokovni terminologiji, ki nemalokrat predstavlja angleško izpeljanko iz drugih jezikov, je pomembna tudi lastna ( $v$ našem primeru slovenska) terminologija oziroma uporaba mednarodne terminologije v lastnem jeziku (tako na primer kljub temu, da izraz doline izhaja iz slovenščine, v slovenskih besedilih uporabljamo besedo vrtača).

Namen članka je, da se zaradi vse bolj obširnega opisa raznolikih kraških pojavov tudi v slovenski literaturi predstavi izbrane osnovne izraze s področja krasa in kraških oblik na kvartarnih eogenetskih kalkarenitih oziroma apnenčevih litičnih peščenjakih. Podoben kras oziroma podobni kraški pojavi so ponekod razviti tudi na starejših eogenetskih kalkarenitih in ostalih karbonatnih eogenetskih kamninah (na primer kalkirudit oziroma konglomerat).

Metodološko je članek zasnovan na pregledu obstoječe literature oziroma na predhodnem poimenovanju obravnavanih pojmov v slovenščini. V kolikor je bilo v slovenščini objavljenih več različnih izrazov za isti pojav, smo v članku uporabil najprimernejšega. Izrazi, ki so že objavljeni v slovenskem geološkem (Pleničar 2006) ali geografskem terminološkem slovarju (Kladnik, Lovrenčak in Orožen Adamič 2005), se tu ne obravnavajo (na primer kalkarenit).

Predstavitev izraza spremlja krajši opis z literaturo za podrobnejše branje. Večina izrazov, ki se jih uporablja v mednarodni strokovni literaturi, izhaja iz angleščine, kar je posledica razvoja takšnega krasa v obalnih predelih Avstralije in Amerike, medtem ko posamezni krasoslovni izrazi v državah, v katerih je razvit podoben kras (na primer Iran, Turčija, Italija), zaradi manj obširnih in pogostih objav v mednarodnih revijah niso prešli v mednarodno strokovno rabo. Poleg novega izraza v slovenščini so omenjeni tudi že uporabljeni slovenski prevodi za določen pojav, pri čemer članek predstavlja izhodišče za slovar iz obravnavane tematike.

\section{Tipi krasa na eogenetskih kvartarnih kalkarenitih}

\subsection{Singenetski kras}

Izraz singenetski kras (angleško syngenetic karst; grško sýn - 'skupaj, hkrati'; grško génesis - 'razvoj, nastanek'; v slovenščini z enakim prevodom omenjen že v članku Liparja (2009)) opredeljuje kras, za katerega sta značilna sočasno zakrasevanje in litifikacija kamnine. Izraz je prvi uporabil Jennings (1968), značilen pa je za mlade karbonatne kamnine (kvartar), predvsem za eolski, obalni in morski kalkarenit (slika 1A) (Grimes 2006).

Renault $(1958 ; 1968)$ je sicer uporabil izraz singenetski za splošne freatične jamske rove kot nasprotje paragenetskim, a je bilo večkrat predlagano, da se tako poimenovanje jamskih rovov opusti (Pasini 2009; 2012).

V literaturi je pojav opisan predvsem na podlagi obalnega pasu južne in zahodne Avstralije (Jennings 1968; Grimes 1994; 2002; 2006; 2009a; Twidale in Bourne 2000; White 2000; White s sodelavci 2007; Lipar 2009), medtem ko je iz drugih predelov sveta za podoben kras uporabljen predvsem izraz eogenetski kras (poglavje 2.2), povezava s singenetskim krasom pa je zgolj omenjena (Vacher in Mylroie 2002; Bella 2007; Ginés in Ginés 2007). Čeprav oba izraza zelo sovpadata, je vseeno potrebna pazljivost pri 
opredelitvi, ali je kamnina v eogenetski fazi še vedno $\mathrm{v}$ fazi litifikacije, ali pa se je ta že končala in je kamnina trenutno podvržena zgolj zakrasevanju, pri čemer bi bila uporaba izraza singenetski kras napačna.

Grimes (2006) razlikuje zgodnjo in pozno fazo singenetskega krasa (slika 2). V zgodnji fazi cementacija poteka predvsem okrog korenin, pri čemer nastajajo rizoliti (slika 1B) (angleško rhizoliths), in takoj pod površjem, kjer se tvori kalkret (slika 1C) (angleško calcrete, kanker, caliche, cap-rock; v prevodu angleškega izvlečka članka Blackwell (2006) se sicer uporablja izraz kalcitna skorja, vendar se kot opisno ta izraz pojavi tudi v geološkem terminološkem slovarju pri opisu stromatolitov (Pavšič 2006); pozneje se v prevodu izvlečka članka Erena in Hatipoglu-Bagci-ja (2010) uporablja izraz kalkret). Zaradi slabe cementacije $v$ tej fazi še ni jam oziroma se oblikujejo le izjemoma, pojavljajo pa se že korozijske cevi (poglavje 3.1). Pozna doba singenetskega krasa je determinirana z močjo cementacije sedimenta - biti mora dovolj močno cementiran, da se v njem lahko oblikuje jama. Pri tem se razvijejo tudi ostali kraški pojavi, pogojeni predvsem z medzrnsko poroznostjo kalkarenita, večinoma počasi tekočo podtalnico in odsotnostjo razpoklinske poroznosti (Grimes 2006).

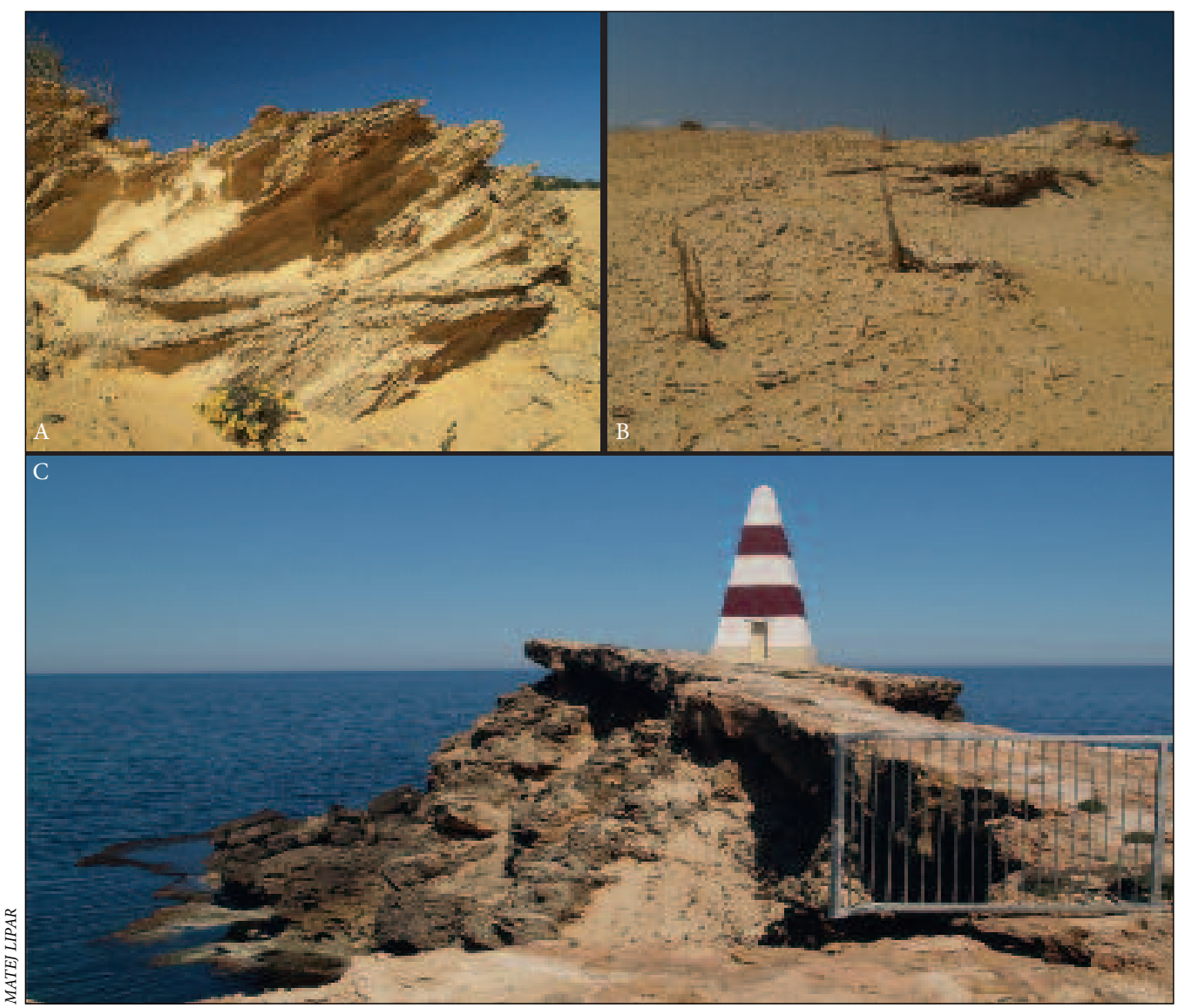

Slika 1: Pleistocenski eolski kalkarenit: $z$ (A) ohranjenimi sledmi sedimentacije peska $v$ različnih naklonih, (B) z ohranjenimi rizoliti, ki so se ohranili zaradi krajevno močnejše cementacije gradiva okrog korenin in posledično večje odpornosti proti eroziji, (C) s plastjo kalkreta kot vrhnjo plastjo, ki je erozijsko odpornejša od nižje ležečih plasti. 
Matej Lipar Prispevek k slovenski terminologiji krasa in kraških oblik na eogenetskih kvartarnih ...
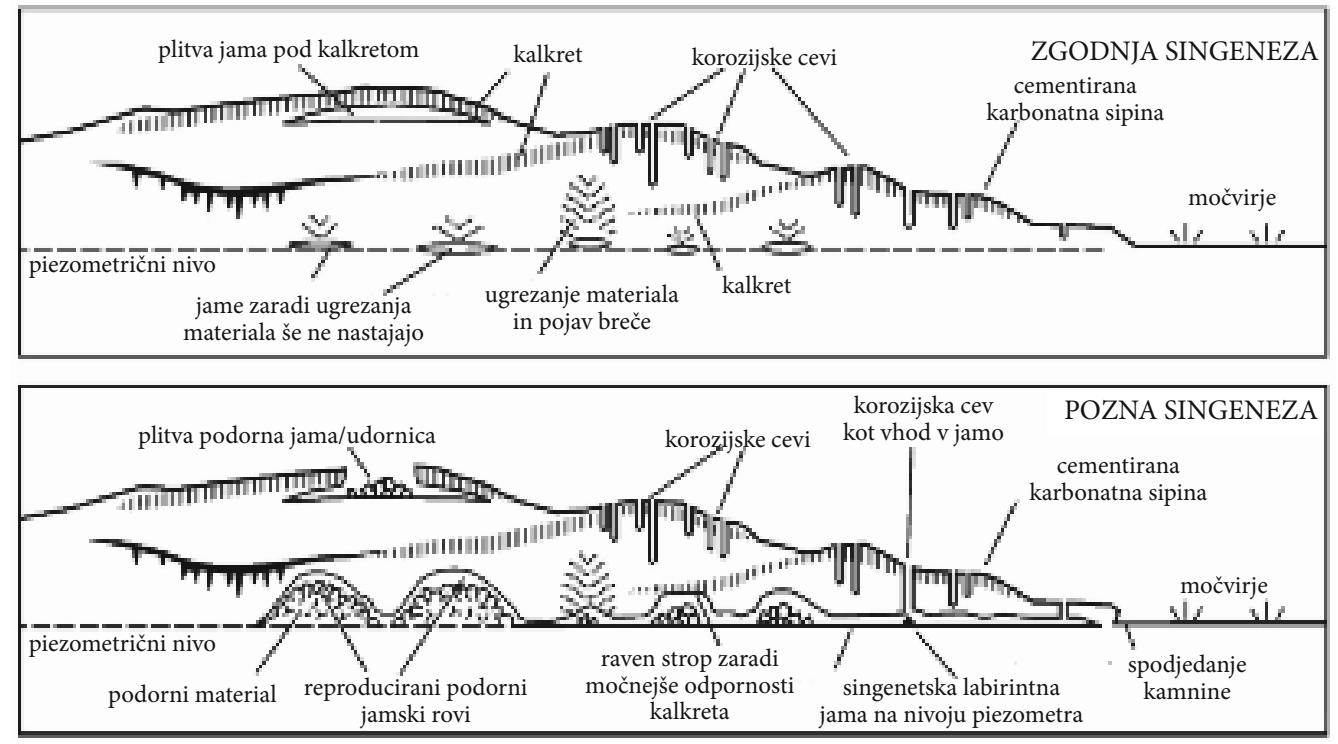

Slika 2: Značilnosti površinskih in podzemnih oblik ter njihove razlike v času zgodnje in pozne singeneze (na podlagi slike v Grimes (2006)).

\subsection{Eogenetski kras}

Izraz eogenetski kras (angleško eogenetic karst; grško eo - 'svit, zora'; v slovenščini enako uporabljen pri Ferkovi in Liparju (2012)) označuje kras, ki se je razvil v eogenetskih karbonatih oziroma karbonatih, ki so v eogenetski fazi (slika 3). Izraz eogenetski oziroma eogenetska diageneza sta uporabila

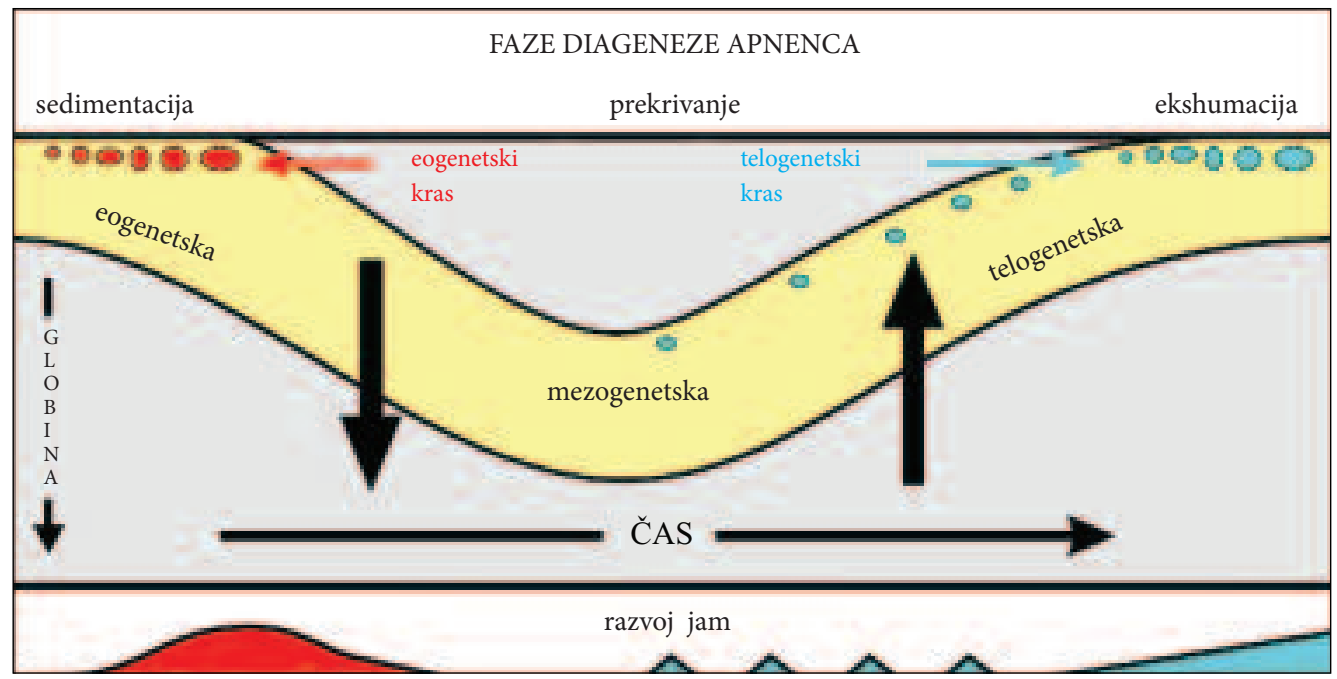

Slika 3: Diageneza apnenca na podlagi Choquette in Pray-evih (1970) faz s ponazoritvijo razvoja krasa (na podlagi slike v Grimes (2009b)). 
Choquette in Pray (1970) in se nanaša na procese, ki vplivajo na nedavno odložen karbonatni ali evaporitni sediment, še preden je ta prekrit. Pomembna procesa sta raztapljanje in cementacija - raztapljanje oziroma menjava kalcita $\mathrm{z}$ večjim deležem magnezija ter aragonita s kalcitom. Ko je sediment prekrit, nastopi mezogenetska faza diageneze (grško mesos - 'srednji'; v slovenščini enako uporabljen pri Ferkovi in Liparju (2012)) (slika 3). Zaradi posledice litostatičnega pritiska v tej fazi v sedimentu potekajo nadaljnja cementacija, rekristalizacija in raztapljanje. Zadnja, telogenetska faza (grško télos 'konec, skrajni del'; enako prevedena v izvlečkih člankov Mylroie, Mylroie in Nelsona (2008), Otoničarja s sodelavci (2010) ter Ferkove in Liparja (2012)) (slika 3) nastopi, ko zaradi dviga in/ali erozije zgornje plasti apnenec zopet postane izpostavljen zunanjemu okolju oziroma eksogenim procesom (Choquette in Pray 1970).

V nasprotju z izrazom singenetski kras, ki je najmočneje zastopan v Avstraliji, je izraz eogenetski kras pogosteje v rabi v Ameriki (predvsem na primerih krasa iz Floride, Bermudov in Bahamov) (Mylroie s sodelavci 2001; Vacher in Mylroie 2002; Florea in Vacher 2006; Smart s sodelavci 2006; Moore, Martin in Screaton 2009) in Evropi (Ginés in Ginés, 2007; De Waele, Mucedda in Montanaro 2009; De Waele, Lauritzen in Parise 2011; Lipar in Ferk 2011).

\subsection{Kras mehkih kamnin}

V močni korelaciji s singenetskim in eogenetskim krasom obstaja tudi izraz kras mehkih kamnin (angleško soft-rock karst; prevoda v slovenščino še ni bilo) (Grimes 2006; Ginés in Ginés 2007). Označuje kras, ki se je razvil na slabo cementirani in navadno medzrnsko močno porozni kamnini. Običajno so te kamnine $\mathrm{v}$ fazi eogenetske diageneze, vendar to ni nujno. Nasprotje opisanega izraza je izraz kras trdnih kamnin (angleško hard-rock karst; prevoda v slovenščino še ni bilo), kjer je cementacija kamnine močna, pronicanje in podzemni pretok vode pa navadno usmerja razpoklinska poroznost kamnine. Zaradi splošnega terenskega vidika in nejasne definicije meje med »trdno« in »mehko« kamnino, je ta izraz omejen predvsem na poljudno, strokovno in jamarsko literaturo, $v$ znanstveni pa ga je priporočljivo dodatno opredeliti oziroma uporabiti drugega.

Vsi trije opisani izrazi se med seboj le delno, vendar dejansko pogosto ujemajo oziroma prepletajo in imajo podobne reliefna oblike. Singenetski kras označuje zakrasevanje z vidika sočasnega delovanja dveh različnih procesov (litifikacije in zakrasevanja), eogenetski z vidika diageneze kamnine, kras mehkih kamnin pa z vidika mehanske lastnosti kamnine. Kras in kraški pojavi, ki so značilni za singenetski ali eogenetski kras oziroma kras mehkih kamnin, so ponekod opisani tudi brez uporabe izrazov (Livingston 1944; Coetzee 1975; Lundberg in Taggart 1995; Waterstrat s sodelavci 2010). V tem primeru je poudarek zgolj na kraški geomorfologiji, hidrologiji. Le-te temeljijo na predhodno opisanih lastnostih kamnine.

\section{Reliefne oblike}

\subsection{Korozijske cevi}

Korozijske cevi (angleško solution pipes; izraz korozijska cev je za tovrstne oblike uporabil Gams (1971), medtem ko je bil v članku Morawiecke in Walsha (1997) uporabljen izraz korozijsko brezno oziroma geološke orgle, ki pa so v slovenskem jeziku opredeljene kot oblika pokritih škrapelj (Gams 1971 ) in posledično neprimeren izraz za korozijske cevi eogenetskih kvartarnih kalkarenitov; pozneje v slovenskem izvlečku članka Bosák s sodelavci (1999) izraz ni bil preveden in se je uporabil angleški izraz, medtem ko se v prevodu angleškega izvlečka člankov Bosáka (2000) in Liparja (2009) zopet pojavi izraz korozijska cev - pri Bosáku (2000) gre sicer za prevod različnih reliefnih oblik z enakim angleškim

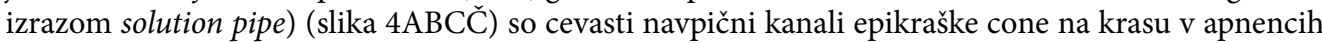


Matej Lipar Prispevek k slovenski terminologiji krasa in kraških oblik na eogenetskih kvartarnih ...

z medzrnsko poroznostjo (predvsem kalkarenitov). Kot sopomenke za korozijsko cev oziroma sorodne oblike se v angleški literaturi uporabljajo izrazi dissolution pipes, solution chimneys, shafts, pits in geological organs (Grimes 2009a), vendar se ti pogosto uporabljajo tudi za poimenovanje drugih navpičnih kraških kanalov.

Obstoječa literatura opisuje korozijske cevi iz zahodnega in južnega obalnega dela Avstralije (Fairbridge 1950; Boutakoff 1963; Jennings 1968; Grimes 1994; 2006; 2009a; White 2000; Lipar s sodelavci 2015), Južne Afrike (Coetzee 1975), Karibov (Lundberg in Taggart 1995; Mylroie in Carew 1995), Bermudov (Herwitz 1993), Irana (Bosák s sodelavci 1999), Sirije (Day 1928), Združenega kraljestva (West 1973) in Italije (Marsico s sodelavci 2003; De Waele, Mucedda in Montanaro 2009; De Waele, Lauritzen in

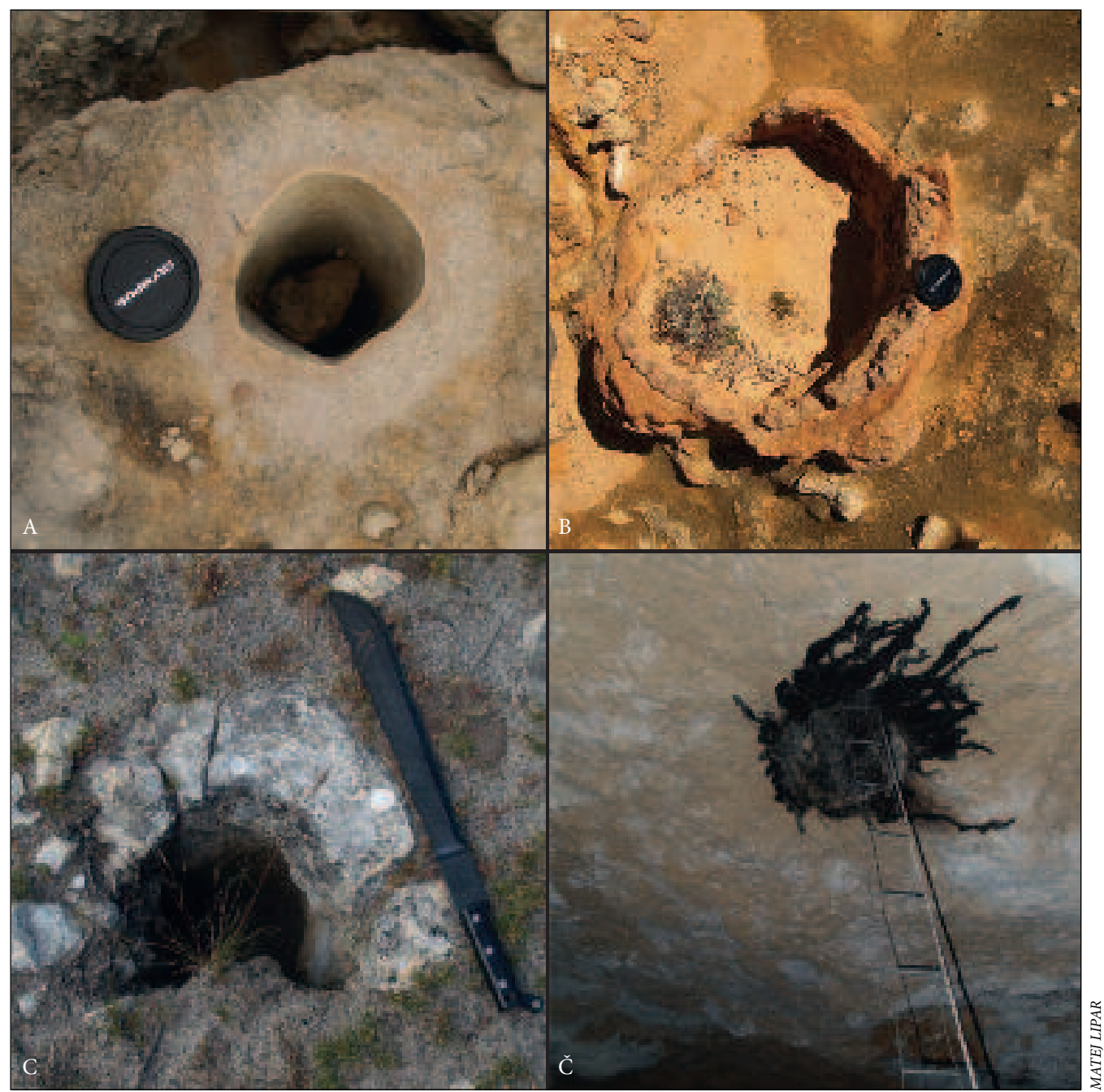

Slika 4: Korozijska cev: $z$ (A) vidno erozijsko odpornejšo notranjo plastjo, (B) z dvojno erozijsko odpornejšo notranjo plastjo, ki zaradi erozije okoliškega gradiva izstopa na površju, hkrati pa je zapolnjena z gradivom, pri čemer je izgubila vlogo odvoda vode v podzemlje, (C) kot aktivni kraški kanal, kakršsen se odraža na površju, (Č) s povezavo z jamskim prostorom, pri čemer je korozijska cev navpični vhod v jamo. 
Parise 2011). Njihova širina (premer) in globina močno variirajo, lahko so širše od metra (Grimes 2009a) in globlje od 20 metrov (Jennings 1968). Lahko se pojavljajo posamično ali v skupinah, pri čemer nastanek dveh ali več v neposredni bližini lahko pripelje do združitve. Premer votline je navadno enakomeren, konča pa se z rahlo zašiljeno-zaobljenim koncem. Drugačni konci (na primer koničasti) so redki, lahko pa se zgodi, da so korozijske cevi povezane z jamskimi rovi, pri čemer se kot samostojni kraški pojav končajo na stropih spodaj ležečih jamskih prostorov (slika 4Č). Korozijska cev ima pogosto močneje cementirano in erozijsko odpornejšo steno od okoliškega gradiva oziroma matične kamnine (slika 4ABC) (Lundberg in Taggart 1995; Grimes 2009a; De Waele, Lauritzen in Parise 2011; Lipar s sodelavci 2015).

Za nastanek korozijskih cevi, ki se začne v zgodnji fazi singenetskega krasa (Grimes 2006), je bistven koncentriran tok agresivne vode, ki ponika v poroznem apnencu (kalkarenitu). Koncentracija toka vode je lahko rezultat zbiranja vode v drevesnih krošnjah in toka po deblu (Herwitz 1993), podzemnega delovanja rastlinskih korenin in nekaterih živali (bioturbacija) (Jennings 1968), površinskih lukenj (Coetze 1975), neenakomerne poroznosti kankerja v začetni razvojni stopnji (Grimes 2006), inicialnega koncentriranega toka vode $v$ še nesprijetem sedimentu (Grimes 2009a) ali zasutih drevesnih debel (Boutakoff 1963). Kateri od naštetih je bistven dejavnik za oblikovanje korozijskih cevi, je zaenkrat še vedno predmet razprave, pri čemer velja omeniti tudi poligentski vidik (Grimes 2009a; Lipar 2009). Megarizoliti (angleško megarhizoliths; prevoda v slovenščino še ni bilo), opisani na Kanarskih otokih, so podobnih oblik kot korozijske cevi, vendar v povprečju manjših dimenzij (Alonso-Zarza s sodelavci 2008). Avtor jih je drugače poimenoval verjetno zaradi razlage načina njihovega nastanka, to je s podzemnim delovanjem rastlinskih korenin. To pa sovpada tudi z eno od možnih genez korozijskih cevi, kar bi megarizolite opredelilo zgolj kot drugoten izraz za korozijske cevi.

\subsection{Stolpiči}

Stolpiči (angleško pinnacles; v slovenski literaturi so podobni pojavi, predvsem v povezavi z geomorfnimi pojavi na Kitajskem, omenjeni kot kamniti gozdovi ali kamniti stebri (Kranjc in Liu 2001; Knez in Slabe 2001), medtem ko so v izvlečku članka Marsica s sodelavci (2003) prevedeni zgolj kot stebri; slovenski prevod stolpičev singenetskega oziroma eogenetskega krasa se v obliki stolpiči pojavi pri Liparju (2009)) (slika 5AB) singenetskega oziroma eogenetskega krasa so apnenčasti stebri, ki delno spominjajo na stolpiče klasičnega krasa. Literatura, ki jih opisuje, je lokacijsko omejena predvsem na Avstralijo, natančneje na jugozahodno obalo Zahodne Avstralije (Lowry 1973; McNamara 1995; Hearty in O'Leary 2008; Grimes 2009a; Lipar 2009; Hearty in Olson 2011; Lipar in Webb 2015), omenjeni pa so tudi kot del eogenetskega krasa v Portoriku (Taboroši in Kázmér 2013) in na Gvamu (Taboroši, Jenson in Mylroie 2004; Mylroie s sodelavci 2012).

Stolpiči so do 5 metrov visoki in do 2 metra široki ter različnih oblik: koničasti, zaobljeni, v obliki gobe ali pa $\mathrm{z}$ več vrhovi. Pojavljajo se v skupinah z medsebojno razdaljo med 0,5 in $5 \mathrm{~m}$. V njih se pojavljajo različne sedimentne plasti, kot plasti kalkarenita s sedimentacijskimi strukturami sipine (slika 5B), kalkreta in rdečkaste fosilne prsti z rizoliti (Lipar in Webb 2015).

Njihov razvoj je predvsem rezultat korozijskega širjenja korozijskih cevi, nekateri stolpiči pa predstavljajo inverzno topografijo krasa; močneje cementirano gradivo v paleo-kraških navpičnih kanalih, danes izraženih kot stolpiči, medtem ko se je okoliška manj odporna kamnina korodirala (Lipar in Webb 2015).

\subsection{Kraške jame}

Klasifikacija kraških jam v povezavi z eogenetskim oziroma singenetskim krasom je raznolika, saj pri združevanju klasifikacij različnih avtorjev nekateri sicer različni tipi jam sovpadajo, spet drugi pa so si po izrazu podobni, vendar imajo drugačen pomen. V nadaljevanju bodo zato omenjene zgolj najbolj značilne jame opisanega krasa. 


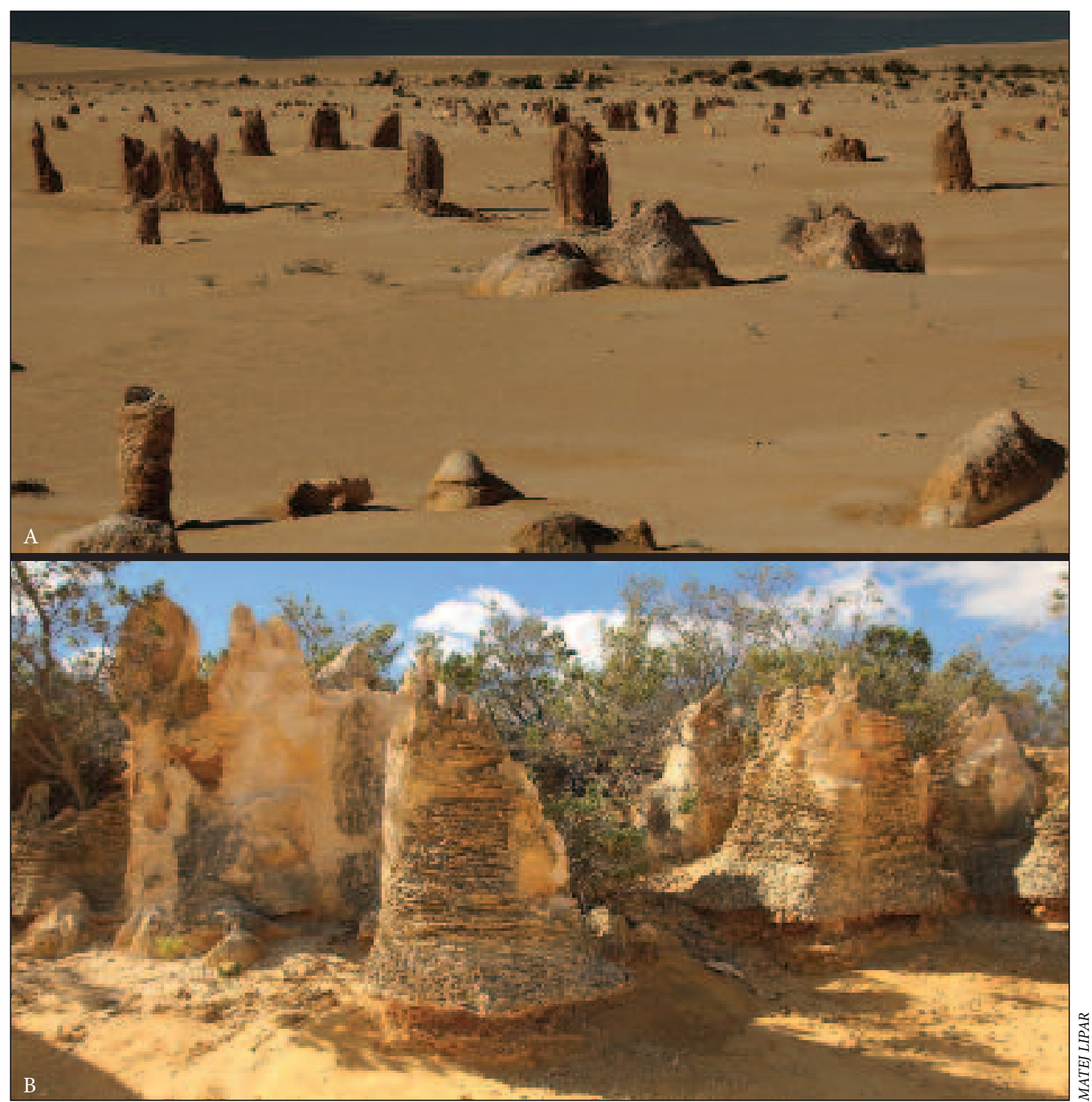

Slika 5: Stolpiči: $z$ (A) močno cementiranim gradivom, (B) s sedimentacijskimi strukturami gradiva (peska) in plastjo paleoprsti na dnu.

Singenetske labirintne jame (angleško syngenetic maze caves; v slovenskem izvlečku članka AlMalabeha s sodelavci (2008) so maze caves prevedene kot blodnjaki, v izvlečku članka Piccini-ja (2011) pa kot labirintne jame) (slika 6) nastanejo navadno na apnencu (na primer kalkarenitu), kjer odsotnost inicialnih razpok nadomešča medzrnska oziroma matrična poroznost kamnine, tok podzemne vode pa je počasen. Na ravni piezometra se oblikujejo široki in nizki, medsebojno povezani rovi ter dvorane nepravilnih oblik (Grimes 2006).

Linearne epifreatične jame (angleško linear stream caves; enak prevod je uporabljen pri opisu eogenetskih konglomeratnih jam v Sloveniji (Ferk in Lipar 2012)) (slika 7) so rezultat vpliva topografije neprepustne podlage oziroma paleoreliefa. Podzemna voda se lahko koncentrira v paleodolinah, ali pa se koncentrira zaradi večjega naklona neprepustne podlage. Pri tem nastajajo v splošnem linearni 


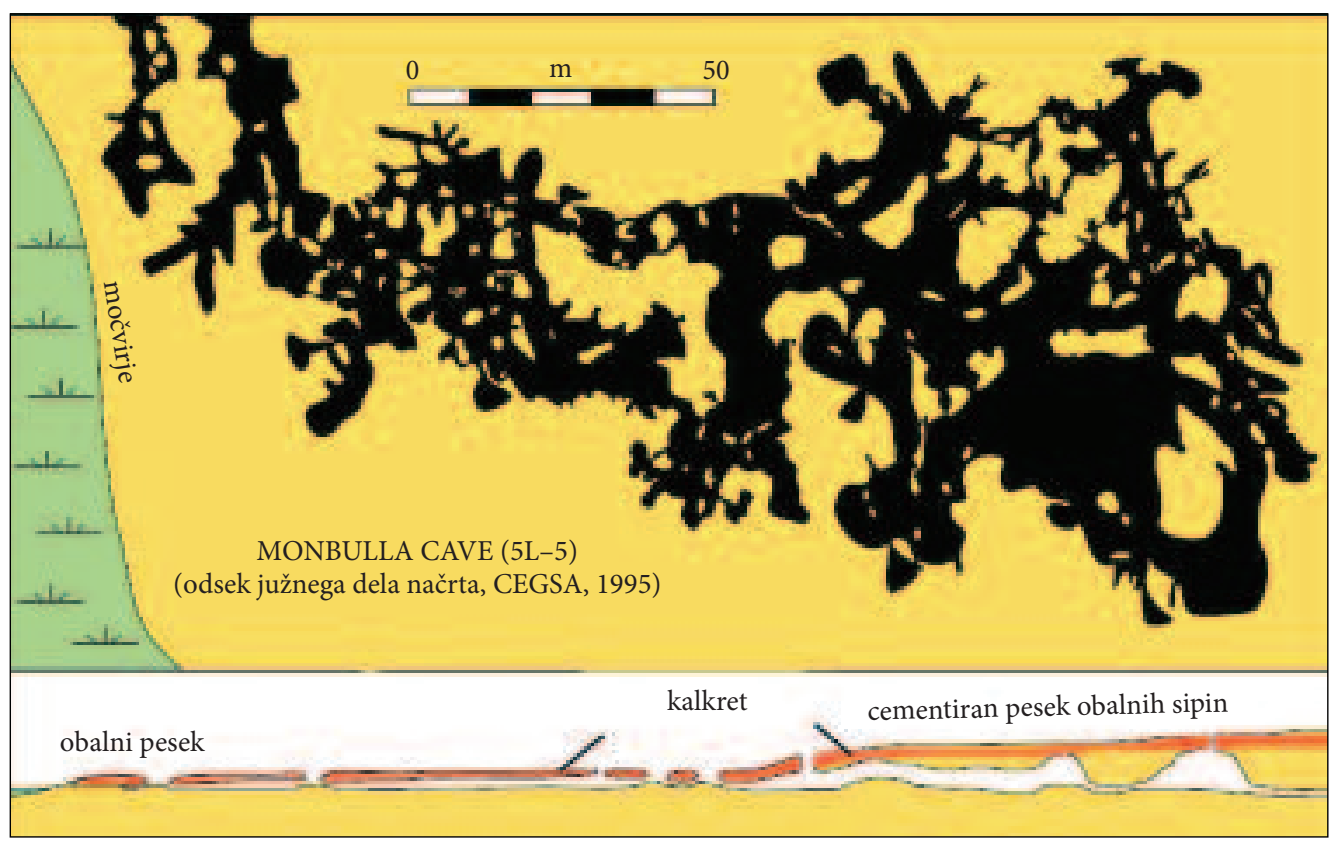

Slika 6: Primer tlorisa in prereza singenetske labirintne jame (na podlagi slike v Grimes (2009b)).

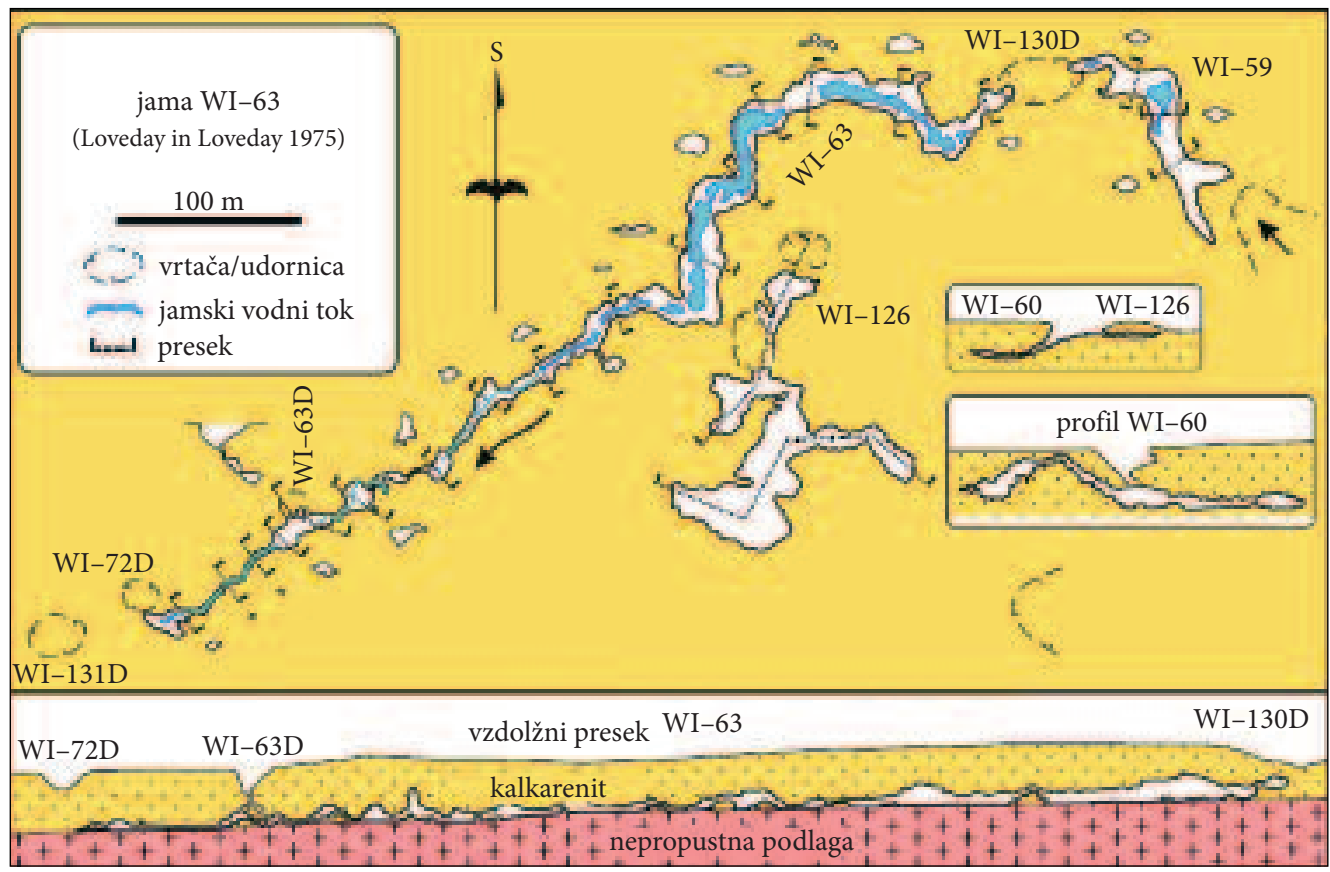

Slika 7: Primer tlorisa in prereza linearne epifreatične jame (na podlagi slike v Grimes (2009b)). 
Matej Lipar Prispevek k slovenski terminologiji krasa in kraških oblik na eogenetskih kvartarnih ...

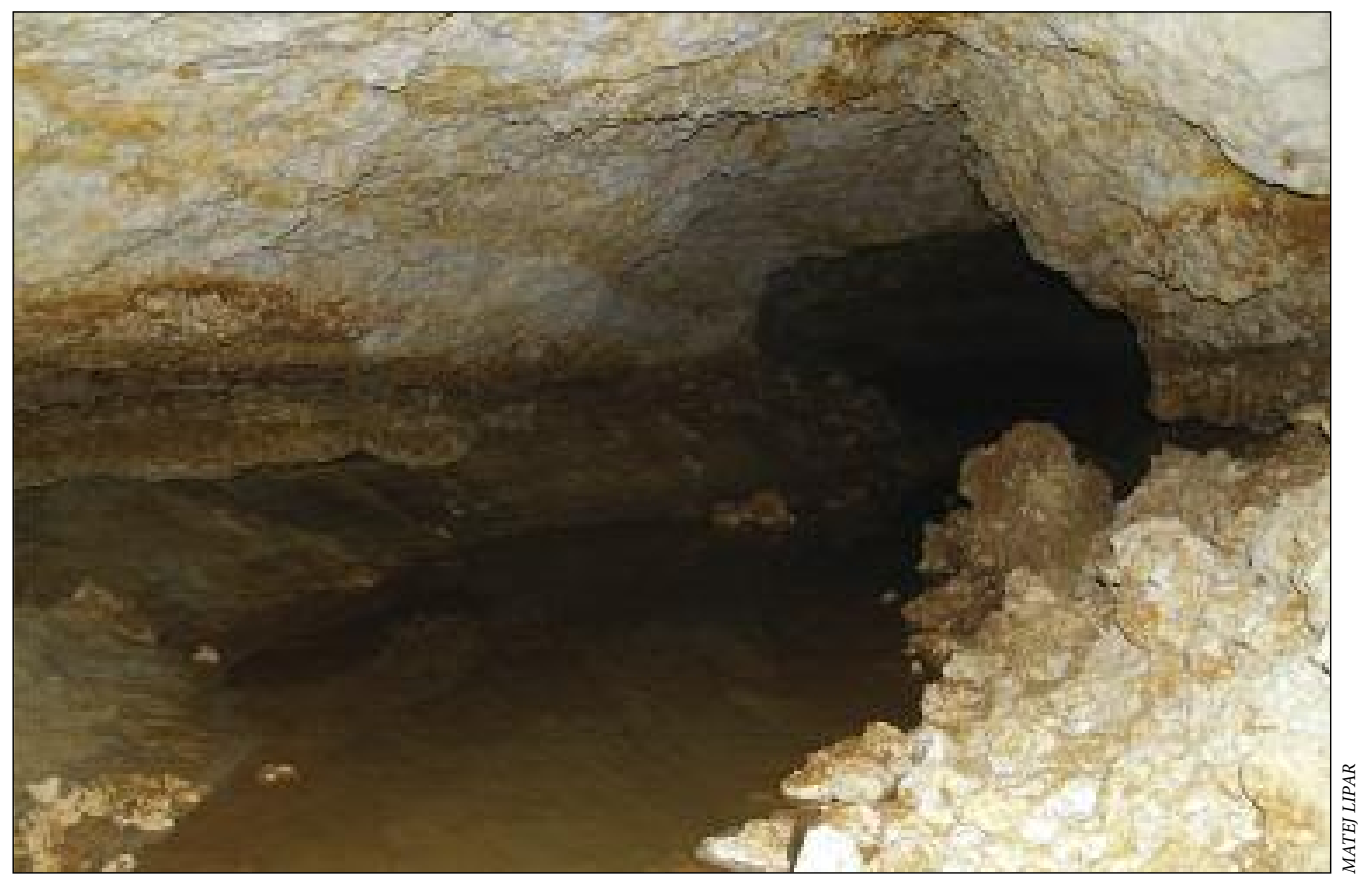

Slika 8: Tunelski epifreatični rov v linearni epifreatični jami Old River Cave v Zahodni Avstraliji.

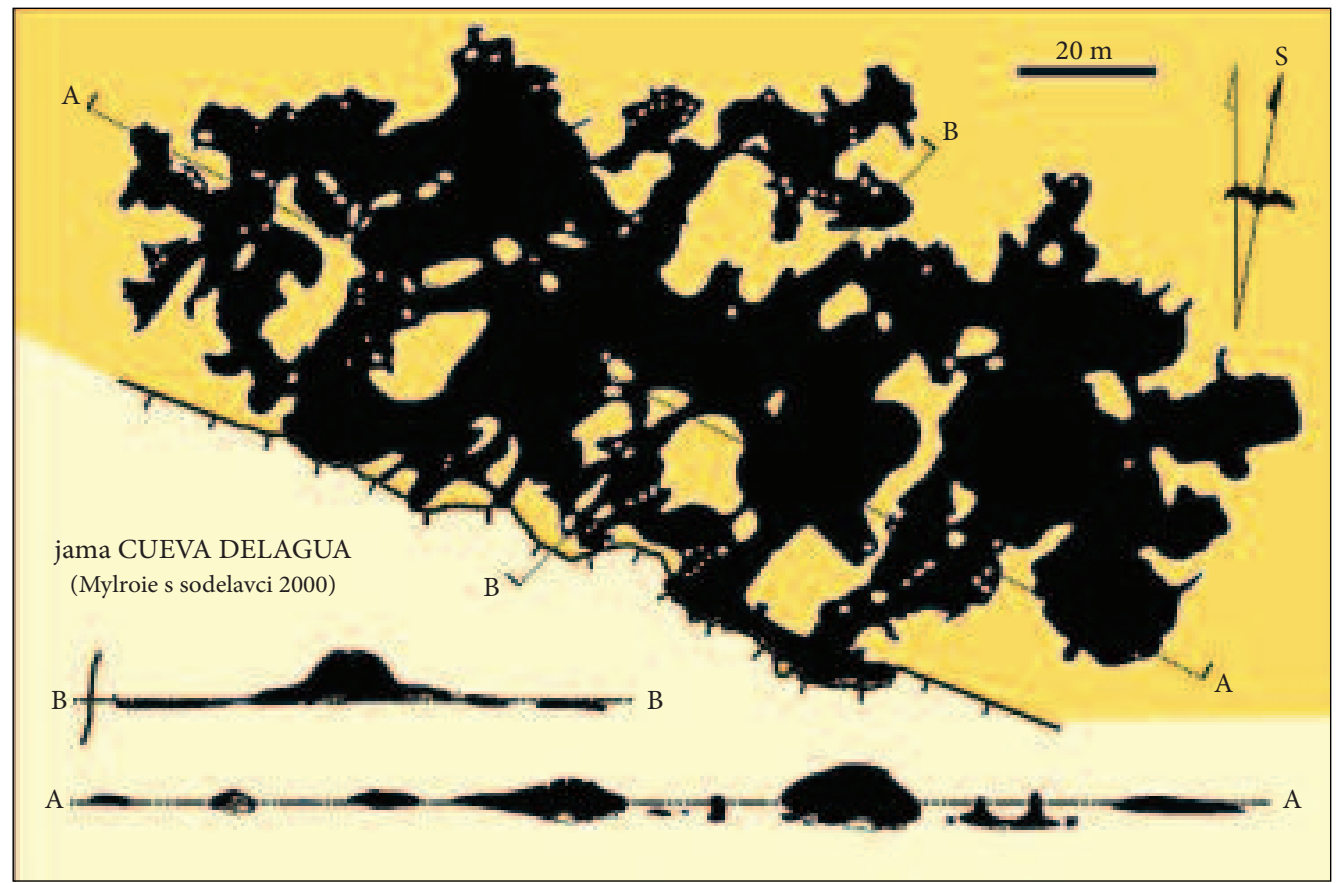

Slika 9: Primer tlorisa in prereza vzdolžno-robne jame (na podlagi slike v Grimes (2009b)). 
tunelski jamski rovi na ravni piezometra (slika 8) (Bastian 1964; 2003; Jennings 1968; Grimes 2006). Podobno ime za jame, ki so nastale na kontaktem krasu, kjer voda teče v jamo točkovno, je uporabil Mylroie s sodelavci (2001), in sicer hidrološko aktivne jame (angleško stream caves; prevoda v slovenščino še ni bilo). Podobne jame je opisal Stafford s sodelavci (2005), pri čemer so bili vodilo linearnega razvoja jamskega sistema $v$ jami razpoke in prelomi, jame pa je opredelil kot razpoklinske jame (angleško fissure caves; v izvlečku članka Kneza, Slabeta in Šebele (2004) so bile fissure caves - sicer na telogenetskem krasu, torej druga vrsta jam - prevedene kot špranjaste jame).

Vzdolžno-robne jame (angleško flank margin caves; v izvlečkih člankov Bosáka s sodelavci (2002) in Otoničarja s sodelavci (2010) prevedeno kot jame tipa »flank margin«) (slika 9) so poseben tip obalnih jam, ki so nastale na ravni mešane korozije sladke in slane vode. So nepravilnih oblik s širokimi in navadno

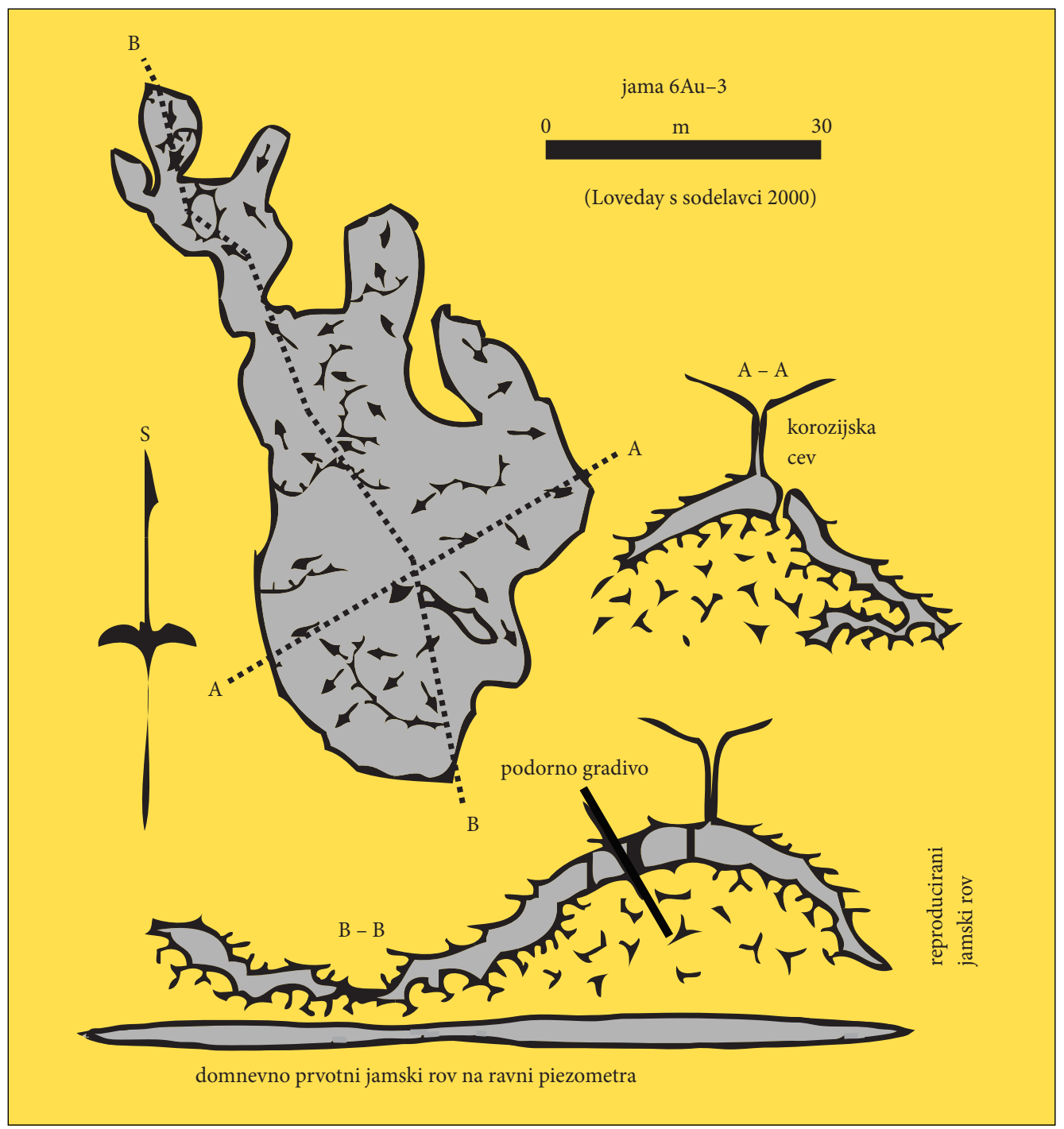

Slika 10: Primer tlorisa in prereza podorne jame in nagnjene reže (na podlagi slike v Grimes (2006)). 
nizkimi, medsebojno povezanimi prostori, po dolžini vzporednimi z obalo (Vacher in Mylroie 2002; Grimes 2006).

Kot podorne jame (angleško breakdown caves; enak prevod je uporabljen pri Ferkovi in Liparju (2012)) (slika 10) se navadno klasificira tiste jame, ki so skoraj v celoti reproducirane s podori (Vacher in Mylroie 2002). V sklopu teh jam velja omeniti še izraz za reproduciran jamski rov, ki predstavlja del jame ali jamo v celoti. $V$ tem primeru se je zaradi ponavljajočih si podorov odprl vhod v jamo nad podorno cono. Med nakopičenim podornim gradivom, ki ima večjo prostornino kot kompaktna kamnina, in stropom v tem primeru ostane navadno plitev prostor, kar imenujemo nagnjena reža (angleško inclined fissure; prevoda v slovenščino še ni bilo) (Bastian 1964; Jennings 1968; Grimes 2006).

Ne nazadnje so v literaturi opisane tudi krajše plitve jame, kot so plitve jame pod kalkretom (angleško shallow caves beneath cap-rock; prevoda v slovenščino še ni bilo) (slika 2) (Grimes 2006), ki so nastale predvsem $\mathrm{z}$ ugrezanjem ali spiranjem slabo cementiranega peska pod trdnim kalkretom; ali pa plitve podorne jame (angleško banana holes; prevoda v slovenščino še ni bilo) (Harris, Mylroie in Carew 1995; Vacher in Mylroie 2002), ki predstavljajo manjše freatične žepe, reproducirane s podori.

Čas začetka oblikovanja jam v eogenetskem apnenčevem peščenjaku temelji predvsem na času, potrebnem za šibko cementacijo gradiva. Prvi kanali na ravni piezometra nastanejo na začetku pozne dobe singenetskega krasa in so pokazatelj začetka te dobe (Grimes 2006).

Med korozijskimi strukturami so v nekaterih jamah značilne zvonaste vdolbine (angleško bell holes; prevoda v slovenščino še ni bilo) (slika 11). To so centrične vdolbine na jamskih stropih apnencev z medzrnsko poroznostjo, katerih premer in globina se giblje od centimetra pa tudi do več metrov (Tarhule-Lips in Ford 1998; Grimes 2005; De Waele, Plan in Audra 2009; Birmingham s sodelavci 2011). Glede njihovega nastanka je še vedno veliko polemik, predvsem o tem, ali je njihova geneza vezana na freatično ali vadozno cono.

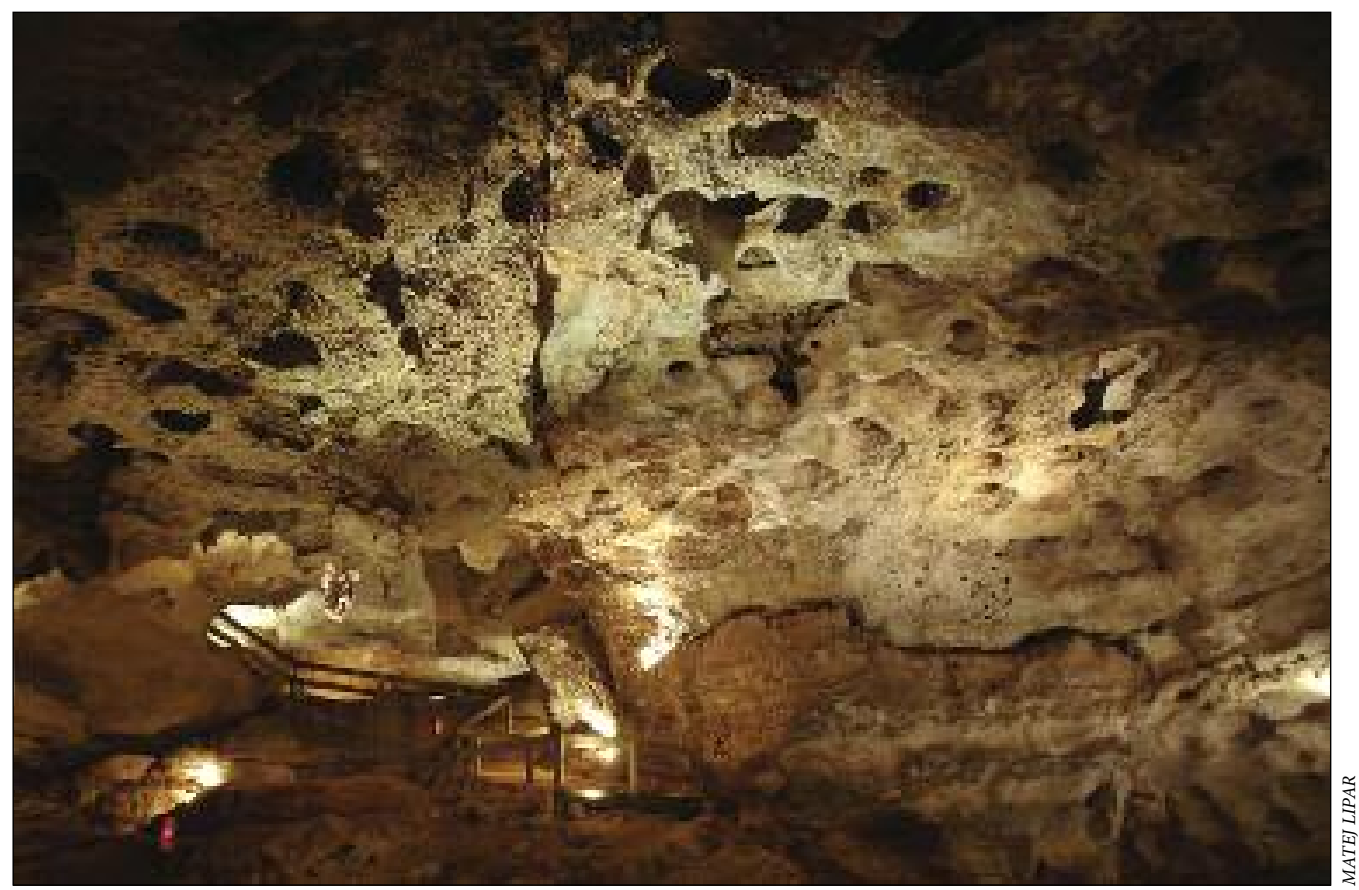

Slika 11: Številčne zvonaste vdolbine na jamskem stropu in stenah v podorni dvorani jame Wet Cave $v$ narodnem parku Naracoorte Caves v Južni Avstraliji. 


\section{Sklep}

Predstavljeni tipi krasa in na njih vezane reliefne oblike obsegajo slovenska poimenovanja in njihove splošne značilnosti. Nekateri slovenski izrazi (preglednica 1) so dobeseden prevod pojmov, nekateri pa so opisni, saj bi dobesedni prevod bodisi sovpadal s kakšnim drugim slovenskim izrazom bodisi ne bi vseboval pravega pomena. Razgibanost jezika (tako slovenščine in angleščine kot drugih jezikov) ponekod dovoljuje odstopanja pri izražanju, zato je kljub danim primerom pomembno, da se, za lažje razumevanje in preprečitev nejasnosti, izrazi v literaturi še dodatno pojasnijo (na primer z genetskomorfološkimi in posledično-pomenskimi opisi).

Preglednica 1: Seznam priporočenih slovenskih izrazov krasa in kraških oblik na eogenetskih kvartarnih kalkarenitih.

\begin{tabular}{ll}
\hline slovenski izraz & angleški izraz \\
\hline eogenetski kras & eogenetic karst \\
hidrološko aktivna jama & stream cave \\
kalkret & calcrete \\
korozijska cev & solution pipe \\
kras mehkih kamnin & soft rock karst \\
kras trdnih kamnin & hard rock karst \\
linearna epifreatična jama & linear stream cave \\
megarizolit & megarhizolith \\
mezogenetski & mezogenetic \\
nagnjena reža & inclined fissure \\
plitva jama pod kalkretom & shallow cave beneath cap-rock \\
plitva podorna jama & banana hole \\
podorna jama & breakdown cave \\
razpoklinska jama & fissure cave \\
rizolit & rhizolith \\
singenetska labirintna jama & syngenetic maze cave \\
singenetski kras & syngenetic karst \\
stolpič & pinnacle \\
telogenetski & telogenetic \\
vzdolžno robna jama & flank margin cave \\
zvonasta vdolbina & bell hole \\
\hline
\end{tabular}

Zahvala: Zahvaljujem se uredniku Matiji Zornu ter dvema anonimnima recenzentoma za opombe in priporočila, ki so močno izboljšali članek. Prav tako se zahvaljujem Mateji Ferk za dolge razprave in izmenjavo mnenj o priporočeni novi slovenski terminologiji ter Kenu Grimesu za posredovanje in dovoljenje objav nekaterih slik vključenih $v$ članek.

\section{Viri in literatura}

Al-Malabeh, A., Kempe, S., Henschel, H. V., Hofmann, H., Tobschall, H. J. 2008: The possibly hypogene karstic iron ore deposit of Warda near Ajloun (Northern Jordan), its mineralogy, geochemistry and historic mine. Acta Carsologica 37-2. DOI: http://dx.doi.org/10.3986/ac.v37i2-3.149 
Alonso-Zarza, A. M., Genise, J., Cabrera, M. C., Mangas, J., Martín-Pérez, A., Valdeolmillos, A., Dorado-Valiño, M. 2008: Megarhyzoliths in Pleistocene aaeolian deposits from Gran Canaria (Spain): Ichnological and palaeoenvironmental significance. Palaeogeography, Palaeoclimatology, Palaeoecology 265, 1-2. DOI: http://dx.doi.org/10.1016/j.palaeo.2008.04.020

Bastian, L. 1964: Morphology and development of caves in the southwest of Western Australia. Helectite 2-4.

Bastian, L. 2003: Hydrogeology and speleogenesis update, the Yanchep Cave Area, Western Australia. 24th Biennial Conference of the Australian Speleological Federation. Perth.

Bella, P. 2007: Geologické a geomorfologické pozoruhodnosti krasu a jaskýň na Bermudách. Aragonit 12.

Birmingham, A. N., Mylroie, J. R., Mylroie, J. E., Lace, M. J. 2011: Bell hole origin: constraints on developmental mechanisms, Crooked Island, Bahamas. Speleogenesis and Evolution of Karst Aquifers 10.

Blackwell, B. A. B. 2006: Electron spin resonance (ESR) dating in karst environments. Acta Carsologica 35-2. DOI: http://dx.doi.org/10.3986/ac.v35i2-3.236

Bosák, P. 2000: The evolution of karst and caves in the Koněprusy region (Bohemian karst, Czech Republic), Part III: collapse structures. Acta Carsologica 29-2.

Bosák, P., Bruthans, J., Filippi, M., Svoboda, T., Šmíd, J. 1999: Karst and cave in salt diapirs, SE Zagros Mts. (Iran). Acta Carsologica 28-2.

Bosák, P., Mylroie, J. E., Hladil, J., Carew, J. L., Slavík, L. 2002: Blow Hole Cave: an unroofed cave on San Salvador Island, the Bahamas, and its importance for detection of paleokarst caves on fossil carbonate platforms. Acta Carsologica 31-3. DOI: http://dx.doi.org/10.3986/ac.v31i3.379

Boutakoff, N. 1963: The Geology and Geomorphology of the Portland Area. Melbourne.

Choquette, P. W., Pray, L. C. 1970: Geological Nomenclature and Classification of Porosity in Sedimentary Carbonates. American Association of Petroleum Geologists Bulletin 54.

Coetzee, F. 1975: Solution pipes in coastal aeolianites of Zululand and Moçambique. Transactions of the Geological Society of South Africa 78.

Day, A. E. 1928: Pipes in the coast sandstone of Syria. Geological Magazine 65.

De Waele, J., Plan, L., Audra P. 2009: Recent developments in surface and subsurface karst geomorphology: an introduction. Geomorphology 106. DOI: http://dx.doi.org/10.1016/j.geomorph.2008.09.023

De Waele, J., Mucedda M., Montanaro L. 2009: Morphology and origin of coastal karst landforms in Miocene and Quaternary carbonate rocks along the central-western coast of Sardinia (Italy). Geomorphology 106. DOI: http://dx.doi.org/10.1016/j.geomorph.2008.09.017

De Waele, J., Lauritzen S. E., Parise M. 2011: On the formation of dissolution pipes in Quaternary coastal calcareous arenites in Mediterranean settings. Earth Surface Processes and Landforms 36. DOI: http://dx.doi.org/10.1002/esp.2022

Eren, M., Hatipoglu-Bagci, Z. 2010: Karst surface features of the hard laminated crust (caliche hardpan) in the Mersin area, Southern Turkey. Acta Carsologica 39-1. DOI: http://dx.doi.org/ 10.3986/ac.v39i1.115

Fairbridge, R. W. 1950: The geology and geomorphology of Point Peron, Western Australia. Journal of the Royal Society of Western Australia 34.

Ferk, M., Lipar, M. 2012: Eogenetic caves in Pleistocene carbonate conglomerate in Slovenia. Acta geographica Slovenica 52-1. DOI: http://dx.doi.org/10.3986/AGS52101

Florea, L. J., Vacher H. L. 2006: Springflow hydrographs: eogenetic vs. telogenetic karst. Ground Water 44-3. DOI: http://dx.doi.org/10.1111/j.1745-6584.2005.00158.x

Gams, I. 1971: Podtalne kraške oblike. Geografski vestnik 43.

Ginés, A., Ginés, J. 2007: Eogenetic karst, glacioeustatic cave pools and anchialine environments on Mallorca Island: a discussion of coastal speleogenesis. International Journal of Speleology 36-2. DOI: http://dx.doi.org/10.5038/1827-806X.36.2.1

Grimes, K. G. 1994: The South-East karst province of South Australia. Environmental Geology 23. DOI: http://dx.doi.org/10.1007/BF00766987 
Grimes, K. G. 2002: Syngenetic and eogenetic karst: an Australian viewpoint. Evolution of Karst: From Prekarst to Cessation. Ljubljana.

Grimes, K. G. 2005: Wet Cave, bell holes. Medmrežje: https://www.researchgate.net/project/Bell-Holes (3.7.2016).

Grimes, K. G. 2006: Syngenetic karst in Australia: a review. Helictite 39-2.

Grimes, K. G., 2009a: Solution pipes and pinnacles in syngenetic karst. Karst Rock Features: Karren Sculpturing. Ljubljana.

Grimes, K. G. 2009b: Syngenetic karst. Poster at 18th Australasian Conference on Cave and Karst Management. Margaret River. DOI: http://dx.doi.org/10.13140/2.1.1001.2805

Harris, J. G., Mylroie, J. E., Carew, J. L. 1995: Banana holes: unique karst features of the Bahamas. Carbonates and Evaporites 10-2. DOI: http://dx.doi.org/10.1007/BF03175406

Hearty, P. J., O’Leary, M. J. 2008: Carbonate aeolianites, quartz sands, and Quaternary sea-level cycles, Western Australia: A chronostratigraphic approach. Quaternary Geochronology 3. DOI: http://dx.doi.org/ 10.1016/j.quageo.2007.10.001

Hearty, P. J., Olson, S. L. 2011: Preservation of trace fossils and molds of terrestrial biota by intense storms in mid-last interglacial (MIS 5c) dunes on Bermuda, with a model for development of hydrological conduits. Palaios 26. DOI: http://dx.doi.org/10.2110/palo.2010.p10-132r

Herwitz, S. R. 1993: Stemflow influences on the formation of solution pipes in Bermuda aeolianite. Geomorphology 6-3. DOI: http://dx.doi.org/10.1016/0169-555X(93)90050-C

Jennings, J. N. 1968: Syngenetic karst in Australia. Contributions to the Study of Karst. Canberra.

Kladnik, D., Lovrenčak, F., Orožen Adamič, M. (ur.) 2005: Geografski terminološki slovar. Ljubljana.

Knez, M., Slabe, T. 2001: Oblika in skalni relief stebrov v Naigu kamnitem gozdu (JZ Kitajska). Acta Carsologica 30-1.

Knez, M., Slabe, T., Šebela, S. 2004: Karst uncovered during the Bič-Korenitka motorway construction (Dolenjska, Slovenia). Acta carsologica 33-2. DOI: http://dx.doi.org/10.3986/ac.v33i2.292

Kranjc, A., Liu, H. 2001: Lunan »shilin« (stone forest) human impact and protection of (eventual) world heritage site (Yunnan, China). Acta Carsologica 30-1.

Lipar, M. 2009: Pinnacle syngenetic karst in Nambung National Park, Western Australia. Acta Carsologica 38-1. DOI: http://dx.doi.org/10.3986/ac.v38i1.134

Lipar, M., Ferk, M. 2011: Eogenetic caves in conglomerate: an example from Udin Boršt, Slovenia. International Journal of Speleology 40-1. DOI: http://dx.doi.org/10.3986/AGS52101

Lipar, M., Webb, J. A. 2015: The formation of the pinnacle karst in Pleistocene aeolian calcarenites (Tamala Limestone) in southwestern Australia. Earth-Science Reviews 140. DOI: http://dx.doi.org/ 10.1016/j.earscirev.2014.11.007

Lipar, M., Webb, J. A., White, S. Q., Grimes, K. G. 2015: The genesis of solution pipes: Evidence from the Middle-Late Pleistocene Bridgewater Formation calcarenite, southeastern Australia. Geomorphology 246. DOI: http://dx.doi.org/10.1016/j.geomorph.2015.06.013

Livingston, W. 1944: Observations on the structure of Bermuda. The Geographical Journal 104, 1-2.

Lowry, D. C. 1973: Origin of the Pinnacles, Nambung, WA. Australian Speleological Federation Newsletter 62.

Lundberg, J., Taggart, B. E. 1995: Dissolution pipes in northern Puerto Rico: an exhumed paleokarst. Carbonates and Evaporites 10-2. DOI: http://dx.doi.org/10.1007/BF03175402

Marsico, A., Selleri, G., Mastronuzzi, G., Sanso, P., Walsh, N. 2003: Cryptokarst: a case-study of the Quaternary landforms of southern Apulia (Southern Italy). Acta Carsologica 32-2. DOI: http://dx.doi.org/ $10.3986 / \mathrm{ac} . v 32 \mathrm{i} 2.344$

McNamara, K. 1995: Pinnacles. Perth.

Moore, P. J., Martin, J. B., Screaton, E. J. 2009: Geochemical and statistical evidence of recharge, mixing, and controls on spring discharge in an eogenetic karst aquifer. Journal of Hydrology 376. DOI: http://dx.doi.org/10.1016/j.jhydrol.2009.07.052 
Morawiecka, I., Walsh, P. 1997: A study of solution pipes preserved in the Miocene limestones (Staszów, Poland). Acta Carsologica 26-2.

Mylroie, J. E., Carew, J. L. 1995: Karst development on Carbonate Islands. Unconformities and Porosity in Carbonate Strata. Tulsa.

Mylroie, J. E., Jenson, J. W., Miklavič, B., Taboroši, D. 2012: Surface and vadose implications of karstification in eogenetic carbonates. Geological Society of America Abstract Programs 44-7.

Mylroie, J. E., Jenson, J. W., Taborosi, D., Jocson, J. M. U., Vann, D. T., Wexel, C. 2001: Karst features of Guam in terms of a general model of carbonate island karst. Journal of Cave and Karst Studies 63-1.

Mylroie, J. E., Mylroie, R. A., Nelson, C. S. 2008: Flank margin cave development in telogenetic limestones of New Zealand. Acta Carsologica 37-1. DOI: http://dx.doi.org/10.3986/ac.v37i1.157

Otoničar, B., Buzjak, N., Mylroie, J., Mylroie, J. 2010: Flank margin cave development in carbonate talus breccia facies: an ecample from Cres Island, Croatia. Acta Carsologica 39-1. DOI: http://dx.doi.org/ 10.3986/ac.v39i1.114

Pasini, G. 2009: A terminological matter: paragenesis, antigravitative erosion or antigravitational erosion?. International Journal of Speleology 38-2. DOI: http://dx.doi.org/10.5038/1827-806X.38.2.4

Pasini, G. 2012: Speleogenesis of the »Buco de Vinchi« inactive shallow hole (Monte Croara karst subarea, Bologna, Italy), an outstanding example of antigravitative erosion (or »paragenesis«) in selenitic gypsum. An outline of the "post-antigravitative erosion «. Acta Carsologica 41-1. DOI: http://dx.doi.org/ 10.3986/ac.v41i1.45

Pavšič, J. (ur.) 2006: Geološki terminološki slovar. Ljubljana.

Piccini, L. 2011: Recent developments on morphometric analysis of karst caves. Acta Carsologica 40-1. DOI: http://dx.doi.org/10.3986/ac.v40i1.27

Renault, P. 1958: Eléments de spéléomorphologie karstique. Annales de Spéléologie 13, 1-4.

Renault, P. 1968: Contribution à l' étude des actions mécaniques et sédimentologiques dans la spéléogenèse. 3e partie: Les facteurs sédimentologiques. Annales de Spéléologie 23-3.

Smart, P. L., Beddows, P. A., Coke, J., Doerr, S., Smith, S., Whitaker, F. F. 2006: Cave development on the Caribbean coast of the Yucatan Peninsula, Quintana Roo, Mexico. Geological Society of America Special Papers 404. DOI: http://dx.doi.org/10.1130/2006.2404(10)

Stafford, K., Mylroie, J., Taboroši, D., Jenson, J., Mylroie, J. 2005: Karst development on Tinian, Commonwealth of the Northern Mariana Islands: controls on dissolution in relation to the carbonate island karst model. Journal of Cave and Karst Studies 67-1.

Taboroši, D., Jenson, J. W., Mylroie, J. E. 2004: Karren features in island karst: Guam, Mariana Islands. Zeitschrift für Geomorphologie 48-2.

Taboroši, D., Kázmér, M. 2013: Erosional and depositional textures and structures in coastal karst landscapes. Coastal Karst Landforms. Dordrecht. DOI: http://dx.doi.org/10.1007/978-94-007-5016-6_2

Tarhule-Lips, R. F. A., Ford, D. C. 1998: Morphometric studies of bell hole development on Cayman Brac. Cave and Karst Science 25.

Twidale, C. R., Bourne, J. A. 2000: Dolines of the Pleistocene dune calcarenite terrain of western Eyre Peninsula, South Australia: a reflection of underprinting? Geomorphology 33. DOI: http://dx.doi.org/ 10.1016/S0169-555X(99)00112-9

Vacher, H. L., Mylroie, J. E. 2002: Eogenetic karst from the perspective of an equivalent porous medium. Carbonates and Evaporites 17-2. DOI: http://dx.doi.org/10.1007/BF03176484

West, I. M. 1973: Carbonate cementation of some Pleistocene temperate marine sediments. Sedimentology 20. DOI: http://dx.doi.org/10.1111/j.1365-3091.1973.tb02047.x

White, S. 2000: Syngenetic karst in coastal dune limestone: a review. Speleogenesis: Evolution of Karst Aquifers. Huntsville.

White, S., Grimes, K. G., Mylroie, J. E., Mylroie, J. R. 2007: The earliest time of karst cave formation. Proceedings of the Time in Karst Conference. Postojna. 
Waterstrat, W. J., Mylroie, J. E., Owen, A. M., Mylroie, J. R. 2010: Coastal caves in Bahamian eolian calcarenites: differentiating between sea caves and flank margin caves using quantitative morphology. Journal of Cave and Karst Studies 72-2. DOI: http://dx.doi.org/10.4311/jcks2009es0086

\section{Summary: A contribution to Slovenian terminology of karst and its features developed in eogenetic Quaternary calcarenites}

(translated by the author)

Slovenian terms of karst types and related geomorphological features are proposed, presented and described. Some Slovenian terms are the exact translation of English terms, whereas others are rather a description of terms as the exact translation could not be made due to overlapping with other Slovenian terms or their misleading meaning. Nevertheless, it is still important that when using certain terms, a short additional description is added to avoid confusion. The variation of language structures (Slovene as well as English) may allow a wide range of expression, yet it can be limited by including other karstological factors, such as genetic, morphologic or resulting components of the features.

The type of karst developed in eogenetic Quaternary calcarenites is termed eogenetic karst (Slovenian eogenetski kras), which refers to the early diagenesis (eogenetic stage) of relatively young, soft and porous carbonates (e.g., calcarenites). Mesogenetic (mezogenetski) stage starts after the sediment is buried, often involving further cementation and re-crystallisation, whereas telogenetic (telogenetski) stage is a final stage and occurs after the uplift when the limestone becomes prone to surface (meteoric) erosion.

The term syngenetic karst (singenetski kras) is used when karstification occurs more or less simultaneously with the sediment lithification, which overlaps in most situations with the term eogenetic karst, but involves different viewpoints. The development of caves and other karst features in the early stage of syngenetic karst is limited as the rock is not lithified enough and subsides at once into any incipient cavities; the cementation in this stage is most apparent around roots (forming rhizoliths; rizoliti) and on the surface (forming calcrete; kalkret). Late syngenesis begins when the rock is sufficiently hardened to support a roof.

The term soft rock karst (kras mehkih kamnin) is used for soft and porous rocks (mostly the ones in eogenetic stage), but it is rather colloquial and should be therefore limited to the caving literature and omitted in the scientific papers.

The most distinctive surface geomorphological karst features in eogenetic Quaternary calcarenites are solution pipes and pinnacles. Solution pipes (korozijske cevi) are vertical tubular karst voids in epikarstic zone, typically 0.3 to $1 \mathrm{~m}$ in diameter and up to $20 \mathrm{~m}$ deep, formed by focussed vertical vadose flow through the permeable sediment with matrix porosity. Their walls may be better cemented than the surrounding calcarenites. The extreme solutional widening and coalescence of solution pipes can lead to the formation of pinnacles (stolpici); they are generally solutional remnants of the original host rock, or cemented infills of solution pipes, where solution in later stage still contributed to their origin by removing the surrounding material.

Numerous types of caves are related to eogenetic/syngenetic karst, and the most common are:

- Syngenetic maze caves (singenetske labirintne jame) with low, branched, horizontal passages;

- Linear stream caves (linearne epifreatične jame) formed by a focused underground flow due to topography, high inclination of the impermeable surface underneath the calcarenites, or fissures, in which case they are termed fissure caves (razpoklinske jame). This kind of caves with an active stream in them can be also be termed stream caves (hidrološko aktivne jame).

- Flank margin caves ( $v z$ dolžno robne jame) of irregular forms of interconnected chambers in coastal environments due to mixing corrosion along the shore; 
- Breakdown caves (podorne jame) where solutional chambers are completely modified by collapses; narrow spaces are often present around the sides of the collapsed domes termed inclined fissures (nagnjena reža);

- Shallow caves beneath cap-rock (plitve jame pod kalkretom) that can form as the first type of caves in early syngenetic stage;

- Banana holes (plitve podorne jame) with shallow, thin-roofed and partly collapsed passages attributed to solution at a shallow watertable.

Bell holes (zvonaste vdolbine) are perhaps the most unique features within the cave ceilings of the syngenetic and eogenetic karst, yet their formation is still not well understood. 